Revista lus et Praxis, Año 24, No 1, 2018, pp. 661 - 692

ISSN 0717 - 2877

Universidad de Talca - Facultad de Ciencias Jurídicas y Sociales

La "valoración negativa" como exclusión de la prueba ilícita en el juicio oral Jorge Cortés-Monroy Fernández

Trabajo recibido el 16 de julio de 2016 y aprobado el 24 de noviembre de 2016

\author{
La "valoración negativa" como exclusión \\ de la prueba ilícita en el juicio oral* \\ "Negative assessment" as eXClusion OF \\ IMPROPERLY OBTAINED EVIDENCE AT THE CRIMINAL TRIAL
}

\author{
Jorge Cortés-Monroy Fernández**
}

\begin{abstract}
RESUMEN
El artículo sostiene que la actividad realizada por los tribunales de juicio oral en lo penal denominada como "valoración negativa de la prueba" no es más que una forma de exclusión de la prueba ilícita, en circunstancias que no parecen encontrarse autorizados para ello. Así, comienza examinando las distintas concepciones sobre la valoración de la prueba, para luego desarrollar uno de los métodos propuestos para maximizar la probabilidad de obtener decisiones correctas sobre los hechos en el proceso penal. Dicho método será aplicado a un caso emblemático, en que los tribunales han "valorado negativamente la prueba". La conclusión será que dicha actividad no puede ser apropiadamente entendida como una valoración de la prueba, pero que encuentra pleno sentido bajo el concepto de exclusión de la prueba ilícita. Así, el artículo finaliza presentando las razones que impiden la exclusión de la prueba en el juicio oral, pero que, además, la hacen indeseable.
\end{abstract}

\title{
ABSTRACT
}

This paper sustains that the practice of the Chilean criminal courts known as "negative assessment of evidence" is nothing but a form of exclusion of improperly obtained evidence in a legal context in which that is not allowed. Accordingly, it begins examining the different conceptions of evidence assessment. Then it develops one of the proposed methods to increase accuracy in fact-finding proceedings. This method will be applied to one of the paradigmatic cases in which criminal courts have negatively assessed the evidence. The conclusion will be that "negative assessment of evidence" cannot be properly taken into account as an assessment of evidence. Instead, it finds its sense in light of the practice of exclusion of improperly obtained evidence. Finally, the paper presents the reasons to consider the exclusion of evidence as a practice that is not only out of the criminal trial courts' purview, but undesirable as well.

\footnotetext{
* Agradezco al profesor Dr. Jonatan Valenzuela Saldías por sus valiosas observaciones a este trabajo.

** Licenciado en Ciencias Jurídicas y Sociales (Universidad de Chile). Investigador Visitante University of Auckland Law School (Auckland, New Zealand). Correo electrónico: jcor454@aucklanduni.ac.nz
} 
Palabras Clave

Valoración negativa, Prueba ilícita, Exclusión e Infracción de derechos fundamentales.

KEY WORDS

Negative assessment, Tainted evidence, Exclusion and Improperly obtained evidence.

Desde que el nuevo sistema procesal penal comenzara a regir en Chile, los tribunales han debido enfrentarse a la aplicación e interpretación de reglas, principios e instituciones que históricamente nos eran extrañas. Esto ha producido ciertas dificultades, especialmente en aquellas situaciones que no han sido reguladas expresamente por el Código Procesal Penal. En ellas, los tribunales se han sentido compelidos a entregar una solución que -en su propia perspectiva- realice los objetivos que originalmente fueron atribuidos a la reforma.

Uno de dichos principios e instituciones ha sido el sistema de libre valoración de la prueba ${ }^{1}$. La aplicación de las normas que lo consagran, ha dado lugar a una práctica problemática denominada -por los propios tribunales- como "valoración negativa de la prueba", que ha sido diseñada para evitar valorar en el juicio oral pruebas que, a pesar de haber sido admitidas por el juez de garantía, han sido obtenidas -a juicio del tribunal de juicio oral-con vulneración de derechos fundamentales.

El objetivo de este trabajo será mostrar que la "valoración negativa de la prueba" no es más que una forma rebuscada de exclusión de la prueba ilícita. Para ello, será primero necesario referirnos a las dos principales concepciones sobre la prueba y a la actividad que su valoración implica. En segundo lugar, se desarrollará uno de los métodos posibles para valorar racionalmente la prueba, que, luego, será utilizado para examinar la idea de la "valoración negativa". La conclusión será que dicha actividad no puede ser entendida propiamente como una forma de valoración, pero, en cambio, encuentra pleno sentido bajo la noción de exclusión probatoria. La última parte del trabajo sostendrá la existencia de argumentos jurídicos y extra-jurídicos que impiden que los tribunales de juicio oral en lo penal excluyan pruebas rendidas en el juicio.

\section{La valoración de la prueba}

A grandes rasgos, existen dos concepciones sobre la prueba y su función en los procesos judiciales en que rige un sistema de libre valoración ${ }^{2}$. La pri-

\footnotetext{
1 La importancia de la adopción de un sistema de libre valoración supera incluso los límites del proceso penal. Véase Maturana (2014), pp. 7 y ss.

2 En los últimos años esta división se ha convertido casi en un lugar común dentro de la literatura especializada. Véase, a modo de ejemplo, AcCAtino (2006), pp. 18 y ss.; Reyes (2012), pp. 236 y ss.
} 
mera, denominada concepción subjetivista, psicologista o persuasiva, entiende la valoración de la prueba como el proceso de determinación de la premisa fáctica del razonamiento jurídico conforme a los estados psicológicos del juzgador de los hechos ${ }^{3}$. En consecuencia, dicha concepción sostiene también una interpretación fuerte del principio de inmediación, que impide la adopción de decisiones sobre los hechos a todo órgano distinto de aquel ante el cual la prueba fue rendida ${ }^{4}$; una exigencia débil de motivación, confinada, a lo sumo, a la expresión de las causas del estado psicológico del juzgador ${ }^{5}$; y el diseño de un sistema de recursos que disminuye la posibilidad de controlar las decisiones probatorias ${ }^{6}$.

La segunda concepción, denominada racionalista o cognoscitivista, entiende la valoración de la prueba como el proceso de determinación de la verdad o falsedad de las proposiciones sobre hechos conforme a las relaciones inferenciales que existen entre ellas y las pruebas disponibles ${ }^{7}$. Aunque la naturaleza específica de dichas relaciones ha sido objeto de debate tanto en la literatura jurídica como filosófica, existe acuerdo en que ellas no dependerían del estado psicológico o mental del sujeto cognoscente ${ }^{8}$.

En consecuencia, la concepción racionalista se caracteriza por una interpretación débil del principio de inmediación, compatible con el control racional de la valoración por parte de un órgano distinto al que presenció la práctica de la prueba ${ }^{9}$; una exigencia fuerte de motivación de la decisión sobre los hechos, que implica la justificación del valor otorgado a las pruebas -individual

\footnotetext{
3 A dicho proceso la doctrina procesalista se refiere como "libre convicción". Véase Ferrer (2007), p. 62.

4 El caso español es particularmente ilustrativo de la relación entre el uso de estados mentales y la "sobrevaloración de la inmediación". Véase Nieva (2012), pp. 31 y ss.

5 FerRer (2011), pp. 89 y ss. En algunos casos ni siquiera se exigirían razones explicativas, limitándose el juzgador de los hechos a pronunciar el veredicto (como en el caso de los jurados en los sistemas anglosajones) o a relatar el modo en que la prueba fue practicada. Esta última situación tuvo lugar, por ejemplo, durante la vigencia de nuestro antiguo procedimiento penal. Véase ACCATINO (2006), pp. 9 y ss.

6 Del Río (2012), p. 250.

7 Dicha concepción tiene una larga tradición en la literatura anglo-sajona. Según TwiNING (2006), p. 110, "La asunción central de la tradición [racionalista] es que las decisiones adjudicativas sobre cuestiones de hecho deben basarse en pruebas y argumentos, típicamente inductivos. En breve, intentamos llegar a juicios justificados respecto de la verdad de las proposiciones de hechos sobre la base de la evaluación racional y el análisis de la evidencia, en orden a promover los fines de la jusicia y/o utilidad". La traducción y los paréntesis son míos.
}

8 De esta forma, ambas concepciones de la prueba parecen ser una manifestación en el contexto jurídico-procesal de la discusión epistemológica más general entre internalistas y externalistas. Véase KING (2000), pp. 1 y ss.

9 Nieva (2012), p. 40. 
y conjuntamente- y su consideración como suficientes o insuficientes ${ }^{10}$; y el diseño de un sistema de recursos que permita el control de la valoración de la prueba y de la decisión sobre su suficiencia ${ }^{11}$.

Existen dos razones para rechazar la concepción subjetivista. La primera es la finalidad de la prueba en contextos jurídicos. Es que el subjetivismo conduce a una de dos posiciones insostenibles: o se afirma (1) que la prueba está orientada a obtener un determinado estado psicológico del juez respecto de los hechos que se pretenden probar, sin importar si ellos han tenido o no verdaderamente lugar en el mundo; o se afirma (2) que la obtención de dicho estado psicológico es la mejor forma de investigar, si los hechos han realmente tenido lugar en el mundo.

Respecto de la primera afirmación, solo diremos que la averiguación de la verdad constituye una condición lógica para la correcta aplicación del Derecho. La prueba debe estar orientada a la determinación de la verdad o falsedad de las proposiciones sobre hechos conforme al estado real de las cosas en el mundo ${ }^{12}$.

Respecto de la segunda idea debemos realizar ciertas precisiones. Los estados mentales requeridos por la concepción subjetivista presentan dos características fundamentales ${ }^{13}$. En primer lugar, son independientes del contexto y siempre responderán a todos los factores (racionales o no) que intervinieron en el proceso cognitivo: un sujeto todavía puede creer en la verdad de " $p$ " no solo a pesar de que " $p$ " es de hecho falso, sino a pesar de toda la evidencia disponible contra la verdad de " $p$ ". En segundo lugar, son involuntarios $y$, por tanto, no susceptibles de justificación. Y es que si la prueba de una proposición depende de que el juez adquiera un estado psicológico determinado (i.e. crea, esté convencido, tenga la certeza moral, no tenga dudas, o cualquier otra formulación equivalente), alcanzado dicho estado mental todo lo demás será irrelevante ${ }^{14}$. Así, se convierte a la decisión judicial sobre los hechos en infalible: si lo que el Derecho exige al juez para declarar probada una proposición fáctica es que crea o esté convencido de su verdad, en tanto tenga dicho estado psicológico no podrá equivocarse.

Esto, evidentemente, es contraproducente si nuestro interés al diseñar reglas probatorias es disminuir el riesgo de arbitrariedad en las decisiones judiciales, e impide considerar que en el proceso judicial (como en todo otro tipo de

10 Ferrer (2011), pp. 93 y ss.

11 FerRer (2007), pp. 62 y ss.

12 Para la justificación de esta proposición véase FERRER (2007), p. 30.

13 Véase Ferrer (2005), pp. 80 y ss.

14 Conforme a una valoración de este tipo la confianza, creencia o convicción del juzgador "precede, certifica, e incluso constituye, la prueba". La expresión es de LAUDAN (2005), p. 106. 
investigación empírica) la valoración subjetiva constituya el método más adecuado para arribar a conclusiones correctas.

En realidad, lo que efectivamente haya tenido o no lugar en el mundo en nada depende del estado psicológico del sujeto cognoscente. En cambio, es alguna característica o propiedad de las pruebas la que debe justificar las decisiones probatorias. Esta necesidad es ilustrada elocuentemente por Larry Laudan:

Uno no debería decirle a cualquier juzgador de los hechos: Usted ha proporcionado una prueba de A cuando está firmemente convencido de A (ni, tampoco: "usted tiene una prueba de A con tal que su confianza subjetiva sea más alta que $X^{\prime \prime}$ ). Al contrario, lo que le decimos es: Usted no está autorizado para estar totalmente convencido de $\mathrm{A}$, a menos que y hasta que usted tenga una prueba de $A$, añadiendo para completar la propuesta que sus firmes convicciones acerca de A no cuentan en absoluto como si tuviese una prueba de A. Y entonces procedemos a decirle cómo sería una prueba de $A^{15}$.

Esta propiedad se refiere a la existencia (o inexistencia) de relaciones inferenciales entre las pruebas y las proposiciones sobre hechos que se pretenden probar, y su determinación se realiza precisamente a través de una valoración racional.

La segunda razón para rechazar la concepción subjetivista es el propio Código Procesal Penal. Dicho código contiene dos artículos fundamentales al respecto. El primero es el artículo 297, que indica lo siguiente:

Valoración de la prueba. Los tribunales apreciarán la prueba con libertad, pero no podrán contradecir los principios de la lógica, las máximas de la experiencia y los conocimientos científicamente afianzados.

El tribunal deberá hacerse cargo en su fundamentación de toda la prueba producida, incluso de aquélla que hubiere desestimado, indicando en tal caso las razones que hubiere tenido en cuenta para hacerlo.

La valoración de la prueba en la sentencia requerirá el señalamiento del o de los medios de prueba mediante los cuales se dieren por acreditados cada uno de los hechos y circunstancias que se dieren por probados. Esta fundamentación deberá permitir la reproducción del razonamiento utilizado para alcanzar las conclusiones a que llegare la sentencia.

El código comienza apelando explícitamente a la racionalidad: Es la lógica, la experiencia y los conocimientos científicos (y no los estados psicológicos del juez), los que permiten establecer el grado de soporte o apoyo inductivo de las proposiciones fácticas ${ }^{16}$.

\footnotetext{
15 Laudan (2005), pp. 104 y ss.

16 Una valoración deductiva e inductivamente válida (i.e. conforme a los principios de la lógica, las máximas de la experiencia y los conocimientos científicamente afianzados) es por definición una valoración racional. Véase Maturana (2014), p. 129.
} 
A su vez, el inciso tercero del artículo 297 exige en su primera parte el señalamiento de las pruebas específicas que apoyan cada una de las proposiciones que se tienen por probadas. Si recordamos que los estados psicológicos como las creencias no son contextuales (i.e. son consecuencia de todos los factores posibles, algunos de ellos irracionales, y otros, profundamente inasibles), dicha exigencia solo tiene sentido si la prueba ha sido valorada racionalmente. Si, en cambio, lo requerido es la creencia o convicción del juez, no será posible atribuir - de una forma no arbitraria- la decisión a uno o varios medios determinados de prueba.

Pero es que, además, la segunda parte del inciso tercero del artículo 297 también supone que la prueba sea valorada racionalmente. Es este tipo de valoración el que proporciona razones intersubjetivamente válidas, permitiendo, así, la "reproducción del razonamiento utilizado". Y es que solo en tanto el proceso probatorio se enfoque en ciertas propiedades de las pruebas podrá ser reproducido (y controlado) por un sujeto distinto al decisor.

Por su parte, el artículo 340 del Código Procesal Penal establece lo siguiente en sus incisos primero y segundo:

Convicción del tribunal. Nadie podrá ser condenado por delito sino cuando el tribunal que lo juzgare adquiriere, más allá de toda duda razonable, la convicción de que realmente se hubiere cometido el hecho punible objeto de la acusación y que en él hubiere correspondido al acusado una participación culpable y penada por la ley.

El tribunal formará su convicción sobre la base de la prueba producida durante el juicio oral.

En su inciso primero, el artículo regula el criterio para decidir sobre la suficiencia de la prueba una vez que ha sido valorada. Esta es la función epistémica de los denominados "estándares de prueba". Sin embargo, la utilización de la expresión "convicción" ha dado lugar a una interpretación subjetivista disonante, con la exigencia explícita de racionalidad establecida en el artículo $297^{17}$.

Aunque esta interpretación subjetivista ha tenido un fuerte apoyo jurisprudencial ${ }^{18}$, ella no es la única posible ni la más adecuada. De hecho, existe una forma de entender el estándar de prueba "más allá de toda duda razonable", compatible con la valoración racional de la prueba. Ella se funda

17 Véase Accatino (2006), pp. 18 y ss.; Accatino (2011), pp. 492 y ss.

18 Véase Cortez (2006), p. 334 y ss.; quien se refiere a diversos fallos en que la Corte Suprema ha señalado que la convicción del tribunal, más allá de toda duda razonable, "es un asunto radicado en el fuero interno de los dirimentes Ilamados a conocer de una determinada materia", siendo la decisión algo que "emana del ámbito de su propia conciencia". De todos modos, esta es una tendencia que parece encontrarse en retirada. 
en la idea de "razonabilidad objetiva", que permitiría interpretar la duda razonable como un concepto compartido, cuya aplicación puede ser controlada intersubjetivamente ${ }^{19}$ :

[L]a referencia a dudas "razonables" admite un sentido normativo que podría indicar que lo relevante no es la presencia o ausencia subjetiva de dudas, sino la presencia o ausencia en el conjunto de elementos de juicio disponibles de ciertas condiciones que debieran razonablemente suscitar una duda ${ }^{20}$.

De conformidad a dicha interpretación, Daniela Accatino, siguiendo a Jordi Ferrer, ha postulado las siguientes condiciones:

(1) La hipótesis debe ser capaz de explicar los datos disponibles, integrándolos de forma coherente, y las predicciones de nuevos datos que la hipótesis permita formular deben haber resultado confirmadas.

(2) Deben haberse refutado todas las demás hipótesis plausibles explicativas de los mismos datos que sean compatibles con la inocencia del acusado, excluidas las meras hipótesis ad hoc ${ }^{21}$.

(3) Que las pruebas de cargo cuya existencia resultara predecible, de acuerdo a nuestros conocimientos previos acerca del mundo, en el caso concreto, hayan sido efectivamente aportadas ${ }^{22}$.

Solo cuando se hayan cumplido dichos requisitos, la duda razonable habrá sido superada y, así, la condena del acusado estará justificada. De esta forma, el artículo 340 no demandaría la utilización de estados mentales como criterios de suficiencia probatoria. Y el éxito del esfuerzo por eliminar la arbitrariedad de las decisiones judiciales sobre los hechos depende de que precisamente no lo haga.

Existe, aún, un último argumento para sostener la exigencia del Código Procesal Penal por racionalidad: si el inciso segundo del artículo 340 (que requiere decidir sobre la base de la prueba producida durante el juicio) ha de ser tomado en serio, la prueba no puede depender de los estados psicológicos del juzgador. Si, en cambio, todo lo requerido es la convicción del tribunal, el número de factores conducentes a dicho estado psicológico no podrá ser conocido ni limitado intencionalmente.

\footnotetext{
19 Sobre la idea de "razonabilidad objetiva" véase MAcCormick (2000), pp. 10 y ss.

20 Accatino (2010), p. 139. Las comillas y las cursivas son de la autora.

21 Ferrer (2007), p. 147; Ferrer (2010), p. 18.

22 ACCATINO (2010), p. 140. Este tercer requisito es agregado por la autora en virtud de la dimensión del peso probatorio.
} 


\section{Metodología de la inducción por eliminación}

Tratándose de una investigación empírica, la valoración de la prueba se efectúa a través de un razonamiento probabilístico orientado a la corroboración de hipótesis conforme a la evidencia ${ }^{23}$. En este contexto, se presenta la inducción por eliminación.

El método de la inducción eliminativa se construye sobre la predicción de eventos o estados de cosas, que son empíricamente contrastables, y que, de ser verdaderas, aportarán apoyo inductivo a las proposiciones fácticas en examen ${ }^{24}$. El siguiente ejemplo será útil para la explicación: Imaginemos que la policía encuentra un cadáver con señales de haber recibido proyectiles disparados con un arma de fuego. Imaginemos, además, que el sujeto A ha sido encontrado en el sitio del suceso. La policía puede, a partir de estas observaciones iniciales, formular la hipótesis de que el sujeto A es el autor del homicidio, y conforme a ella, predecir que se encontrarán residuos nitrados en el cuerpo o vestimentas de este último. Si la predicción resulta correcta, la hipótesis habrá sido corroborada por la prueba y, así, habrá adquirido mayor probabilidad inductiva. Si la predicción no se cumple (i.e. no existen residuos nitrados en el cuerpo o vestimenta del sujeto A), la hipótesis podrá haber sido refutada ${ }^{25}$.

Como puede advertirse, la noción de predicción tiene un rol fundamental. Ella consiste en la formulación de una proposición a partir de la hipótesis y de ciertos supuestos auxiliares, que puede ser contrastada empíricamente mediante la realización del examen adecuado, siempre y cuando se cumplan ciertas condiciones iniciales ${ }^{26}$. Por su parte, los supuestos auxiliares están constituidos por generalizaciones empíricas (que nuestro Código Procesal Penal describe como "máximas de la experiencia y conocimientos científicamente afianzados", y que tienen un grado de corroboración propio que le otorga mayor o menor fuerza a la inferencia), y las condiciones iniciales, por los hechos condicionantes de la predicción ${ }^{27}$.

\footnotetext{
23 El concepto específico de probabilidad que debe utilizarse es un asunto controvertido. Aquí utilizaremos la noción de probabilidad inductiva y el método de la inducción por eliminación. Como más adelante se verá, el rechazo de uno u otro (o de ambos) no perjudica el argumento principal del trabajo.

24 Ferrer (2007), p. 131.

25 El ejemplo es de Ferrer (2007), p. 132.

26 Hempel (1999), pp. 20 y ss., denomina a estas predicciones como "implicaciones contrastadoras de la hipótesis". Ellas son enunciados que describen "hechos observables que se espera se produzcan" si la hipótesis es verdadera.

27 Las condiciones iniciales constituyen el "modo como las cosas son ahora -esto es, antes del ensayo-". BLACK (1984), p. 90.
} 
Así, para que la hipótesis resulte corroborada la predicción formulada, debe cumplirse si la hipótesis, los supuestos auxiliares y las condiciones iniciales (considerados conjuntamente) son verdaderos, y muy probablemente incumplirse si no lo $\operatorname{son}^{28}$. Si ello es así, la prueba (o predicción contrastada) le aportará apoyo inductivo a la hipótesis.

Esto, aplicado al proceso penal, significa que el grado de corroboración (o probabilidad inductiva) de una proposición sobre los hechos estará dado por su capacidad explicativa de los datos o informaciones disponibles, en virtud de las pruebas practicadas durante el juicio. Así, una hipótesis será más probable mientras mayor sea el número y calidad de predicciones formuladas en base a ella que han resultado ser verdaderas conforme a las pruebas rendidas, y que muy probablemente no podrían haberse formulado en base a hipótesis alternativas ${ }^{29}$.

Por último, una vez finalizada la valoración de la prueba y establecido el grado definitivo de corroboración, será necesario determinar si las proposiciones fácticas se encuentran suficientemente probadas. Esta operación se realizará conforme al estándar de prueba establecido en el artículo 340 del Código Procesal Penal.

\section{La valoración negativa de la prueba}

Veamos ahora qué es lo que hace un tribunal de juicio oral en lo penal cuando "valora negativamente la prueba" ${ }^{\prime 30}$. Para ello examinaremos un caso de tenencia ilegal de arma de fuego con su número de serie borrado, cuyo juicio se realizó ante el Séptimo Tribunal de Juicio Oral en lo Penal de Santiago ${ }^{31}$. En este, la acusación alegó los siguientes hechos:

\footnotetext{
28 La cuestión detrás del segundo requisito ("muy probablemente incumplirse si no lo son") es la posibilidad de que la predicción sea explicada por otras hipótesis.

29 FeRRER (2007), pp. 131 y ss.

30 En este punto es necesario realizar una advertencia: nuestra jurisprudencia no ha sido unívoca al utilizar la expresión "valoración negativa". Existe, al menos, un sentido distinto al descrito en este trabajo en que la Corte Suprema ha utilizado el término: "[...] la lectura del motivo séptimo de la sentencia impugnada permite concluir que no es efectivo lo que se afirma, en orden a que se dio una valoración negativa al silencio del acusado en la audiencia de juicio para acreditar o reafirmar su participación en el ilícito". Véase Corte Suprema, rol № 65-2014, de 20 de febrero de 2014, considerando sexto. Así, la Corte estaría utilizando la expresión para referirse a la extracción de inferencias desfavorables para el acusado de la circunstancia de haber permanecido en silencio durante el juicio. Este sentido puede ser interpretado en forma general para sostener, entonces, que cada vez que sobre un elemento de prueba el juzgador extrae inferencias desfavorables a la proposición que se pretende probar, este se encuentra valorándola negativamente. Como resulta evidente, este es un uso no problemático de la expresión.

31 Dicho delito se encuentra previsto y sancionado en el artículo 13 de la Ley № 17.798 de 1977 sobre control de armas, en relación al artículo $3^{\circ}$ de la misma ley.
} 
Cerca de las 16:00 horas del 9 de febrero de 2006, el acusado Carlos Alberto Muñoz Aceituno, fue detenido por funcionarios de la Policía de Investigaciones de Chile, en cumplimiento de una orden judicial de detención emanada del 29 Juzgado del Crimen de Santiago, frente al inmueble ubicado en calle Lenka Franulic $\mathrm{N}^{\circ} 4455$, en la comuna de Macul, siendo posteriormente trasladado a su otro domicilio ubicado en Los Diamelos № 8447, comuna de La Florida, encontrando en el interior de este último inmueble, un revolver marca Smith and Wesson, con su número de serie borrado, seis cartuchos calibre 32 y dos cartuchos calibre $6.35 \mathrm{~mm}$. El arma y las municiones las tenía en su poder el acusado sin la autorización requerida para ello ${ }^{32}$.

Por mor de la exposición, asumiremos que una adecuada interpretación de las normas penales sustantivas requería la ocurrencia de los hechos precisamente en la manera descrita. Así, tres juicios orales fueron realizados: el primero fue resuelto con la absolución del acusado, el segundo con su condena, y el tercero, nuevamente con su absolución. El examen de la prueba en el segundo juicio es particularmente útil para determinar el sentido de la "valoración negativa" y de lo que esta actividad implica en la corrección de las decisiones. En dicho juicio, la prueba presentada por la fiscalía fue la siguiente ${ }^{33}$ :

(1) El testimonio de dos funcionarios de la Policía de Investigaciones que participaron en la detención del acusado y en la incautación del arma de fuego.

(2) La declaración de dos peritos (un armero y un químico) que realizaron los exámenes del arma de fuego.

(3) Como prueba material se presentaron el revólver incautado y las municiones.

(4) Como prueba documental se presentaron dos oficios del departamento de Control de Armas y Explosivos de la Dirección General de Movilización Nacional.

Utilicemos, entonces, el método de la inducción por eliminación expuesto en la sección anterior. Para ello, adoptaremos la perspectiva de quien debe evaluar la prueba rendida.

En primer lugar, si la hipótesis acusatoria fuese cierta, los funcionarios que detuvieron al imputado y hallaron el revólver en su domicilio podrían declarar como testigos en el juicio oral. Dichos funcionarios fueron citados (testigo " $\mathrm{A}$ " y testigo "B") y relataron -en forma conteste- el hallazgo del revolver con el número de serie borrado y de las municiones en el domicilio del imputado (en la

32 Véase Corte Suprema, rol № 678-2007, de 6 de junio de 2007; Séptimo Tribunal de Juicio Oral en lo Penal de Santiago, rol No 148-2006, de 1 de enero de 2007.

33 Véase Séptimo Tribunal de Juicio Oral en lo Penal de Santiago, rol № 148-2006, de 1 de enero de 2007. 
misma forma en que los sostuvo la acusación). Así, considerando la declaración del testigo " $\mathrm{A}$ " corroborada por la declaración del testigo " $\mathrm{B}$ " ( $y$, como veremos, también por las declaraciones de los peritos y por las pruebas materiales), y no siendo controvertidas dichas declaraciones por la defensa, podemos decir que existe una prueba bastante fiable que otorga apoyo inductivo a la hipótesis de que el revólver con el número de serie borrado y las municiones fueron encontrados en el domicilio del acusado.

Y, sin embargo, como jueces podríamos pensar en una explicación alternativa que pondría a los hechos fuera del alcance de la norma penal sustantiva. Así, podríamos decir que el revólver encontrado no se trataba en realidad de un arma de fuego, por no ser apto para el disparo. De esta forma, de ser cierta la hipótesis acusatoria, las pruebas practicadas al revólver mostrarán su aptitud para ser disparado.

En efecto, la fiscalía presentó un perito armero y un perito químico, quienes expusieron los procedimientos científicos aplicados en el examen del revólver y sus resultados. Ambos peritos indicaron que el arma se encontraba apta para ser disparada y por tanto, podía ser considerada como un arma de fuego. El perito químico extrajo dicha conclusión de que en sus exámenes encontró residuos carbonosos y nitrados en el revólver, los que típicamente posee un arma de fuego que ha sido disparada. El perito armero, por su parte, pudo percibir directamente que el arma disparaba mediante las pruebas de funcionamiento que ordinariamente se practican para verificar dicha circunstancia. Las declaraciones de ambos peritos fueron concordantes respecto de este hecho. En consecuencia, existen pruebas fiables y poderosas para dar por probada la hipótesis de que el revólver encontrado en el domicilio del acusado era un arma de fuego ${ }^{34}$.

No obstante, antes de emitir un veredicto condenatorio nuevamente podríamos imaginar una explicación alternativa que demandaría la absolución del acusado: que la tenencia del arma de fuego le correspondía a un tercero y no a él, a pesar de haber sido encontrada en su domicilio. Así, si la hipótesis acusatoria fuese verdadera, podríamos formular otra predicción: que existirán testigos que afirmen que era el imputado quien tenía el arma de fuego ${ }^{35}$. Y es

\footnotetext{
34 DuCE (2010), pp. 76 y ss., describe cuatro requisitos para la admisibilidad de la prueba pericial: (1) la relevancia (requisito general para la admisibilidad de toda prueba), (2) la necesidad, (3) la idoneidad del perito, y (4) la confiabilidad del peritaje. Es interesante notar que por tratarse de criterios epistemológicos relativos a la fiabilidad de la prueba los últimos dos pueden ser examinados también por el Tribunal de Juicio Oral en lo Penal, a pesar de haber sido ya examinados al admitirse al juicio. Así, podrían haberse suscitado dudas respecto de la idoneidad de los peritos y de la confiabilidad de los procedimientos aplicados. De todas formas, no son estas las razones otorgadas por los jueces para absolver.

35 De acuerdo con Politoff (2006), pp. 458 y ss., la tenencia requiere una "esfera de custodia" que implica un "poder autónomo" sobre la cosa. En el caso, el hecho de encontrarse el arma en el
} 
la declaración del testigo "A" la que confirma dicha predicción. El testigo "A" señaló que el imputado le indicó, mientras estaban en el patio de su domicilio, que tenía un arma de fuego en su dormitorio principal. Dicho testimonio fue corroborado por la declaración del testigo "B", quien señaló que llegó con posterioridad al domicilio del acusado pudiendo presenciar la existencia del arma y de las municiones. Siendo coherente con la exposición del testigo "A", el relato del testigo " $\mathrm{B}$ " mejora la credibilidad del primero.

Pero además, si la hipótesis de la tenencia por un tercero fuese verdadera esperaríamos que el acusado declarase en tal sentido en el juicio, o que, al menos, la defensa realizase dicha alegación. Dicha predicción no se cumplió: al inicio del juicio oral el acusado declaró y no hizo referencia alguna a que la tenencia del arma correspondía a otra persona. Tampoco la defensa presentó este argumento. De esta forma, podemos decir que existe una prueba fuerte de que dicha tenencia le correspondía al acusado.

Hasta este punto, el análisis permite tener por corroborada la proposición de que un arma de fuego con el número de serie borrado y cuya tenencia correspondía al acusado fue encontrada en su domicilio, junto con municiones. $Y$, sin embargo, todavía podríamos pensar en una hipótesis alternativa: que este contaba con autorización de la autoridad competente para tener el revólver hallado en su domicilio. En consecuencia, si la teoría de la acusación resultase cierta, podemos predecir que, consultado el registro correspondiente, el acusado no tendría la autorización requerida. Para ello se utilizaron dos caminos inferenciales.

En primer lugar, la fiscalía presentó la declaración del perito químico, quien expuso que a través de ciertos procedimientos técnicos pudo establecer que el número de serie del arma era el 71.250. Consultado dicho número al departamento de Control de Armas y Explosivos de la Dirección General de Movilización Nacional, se obtuvo un primer oficio indicando que el revólver estaba inscrito a nombre de una persona distinta del acusado, quien lo reportó como robado tres años antes de tuvieran lugar los hechos de este caso. En el juicio se dio lectura de dicho oficio.

En segundo lugar, se consultó directamente la información del acusado a la autoridad, obteniéndose un segundo oficio que señalaba que este no poseía armas inscritas en el registro correspondiente y que carecía del permiso para portarlas. Este oficio también fue leído en el juicio. De esta forma, no siendo cuestionada la autenticidad de ambos documentos, tenemos una prueba altamente fiable de que el acusado carecía de autorización para tener el arma de fuego encontrada.

domicilio del imputado junto al reconocimiento como propia parecen bastar para establecer dicho "poder autónomo". 
Así las cosas, todas las circunstancias fácticas sostenidas por la acusación y necesarias para la configuración del delito parecen suficientemente acreditadas. El hallazgo del revólver y de las municiones, y la tenencia de los mismos por parte del imputado, fueron probados por las declaraciones de los dos testigos. El hecho de que el número de serie se encontraba borrado fue probado por las declaraciones de los dos testigos y de los dos peritos (estos últimos agregaron que la causa fue la "acción mecánica"), y con la exposición del revólver ante el tribunal. La circunstancia de que efectivamente se trataba de un arma de fuego (i.e. era apta para el disparo) fue acreditada por la declaración de ambos peritos, quienes expusieron los procedimientos científicos utilizados para llegar a dicha conclusión. Y la falta de autorización del acusado para tener el arma fue probada mediante la declaración del perito químico y los dos oficios de la Dirección General de Movilización Nacional. Por su parte, el dolo y el ánimo de tenencia fueron inferidos de la declaración de los dos testigos, quienes relataron cómo el propio acusado indicó la tenencia del revólver (por lo que tenía pleno conocimiento de ello). Y si todo lo indicado no fuese suficiente, el acusado declaró confirmando la detención realizada en el día y hora señalados y el hallazgo del arma de fuego y las municiones en su domicilio por parte de los funcionarios policiales, incrementando la fiabilidad de las declaraciones y la coherencia del relato.

En la causa, el tribunal realizó un razonamiento similar al descrito, valorando la prueba de un modo racional y cumpliendo lo requerido por el artículo 297 del Código Procesal Penal. Si al resultado de dicha valoración aplicamos el estándar de prueba más allá de toda duda razonable en su lectura objetiva (desarrollada en la primera sección de este trabajo), no podemos más que concluir que debía emitirse un veredicto condenatorio: la hipótesis de la culpabilidad, tal como fue expuesta en la acusación, explica coherentemente los datos disponibles; las predicciones que dicha hipótesis ha permitido formular han resultado confirmadas; y toda otra hipótesis alternativa plausible que sostenga la inocencia del acusado (i.e. que el arma no era apta para el disparo, que la tenencia correspondía a un tercero, que el acusado tenía autorización para tenerla) ha sido refutada. Además, se han aportado todos los elementos que podían preverse como necesarios para la prueba del delito en cuestión de acuerdo al estado actual del conocimiento sobre el mundo.

En efecto, esta es la conclusión a la que llega el Séptimo Tribunal de Juicio Oral en lo Penal de Santiago:

De esta forma, ante la contundencia de la prueba de cargo que lo incrimina de manera categórica y la ausencia de una teoría alternativa capaz de generar siquiera un asomo de duda en los sentenciadores acerca de la participación que tuvo en los hechos el acusado, el Tribunal concluyó que a Carlos Alberto Muñoz Aceituno le correspondió participación en calidad de autor del delito 
de tenencia ilegal de arma de fuego con su número de serie borrado, por el cual fue acusado, desde que intervino en su perpetración de una manera inmediata y directa, de conformidad con lo dispuesto en el artículo 15 número 1 del Código Penal ${ }^{36}$.

En conformidad a ella, se emitió un veredicto condenatorio. Sin embargo, la defensa interpuso un recurso de nulidad fundado en que ciertas pruebas habrían sido obtenidas con infracción de derechos fundamentales del acusado. Y dicho recurso fue acogido porque, en opinión de la Corte Suprema, se habrían infringido las garantías de la inviolabilidad del hogar y del debido proceso, anulándose la sentencia y el juicio oral y ordenándose la celebración de un nuevo juicio ${ }^{37}$.

En el nuevo juicio, se rindieron esencialmente las mismas pruebas, con una diferencia: la fiscalía pudo presentar un tercer testimonio correspondiente a un tercer funcionario de la policía que participó en la detención e incautación, que reforzó la prueba de cargo y corroboró las declaraciones de los testigos " $\mathrm{A}$ " $\mathrm{y}$ "B". Conforme a ello, el tribunal también concluyó que todos los presupuestos fácticos del delito y de la autoría del acusado se encontraban probados por la acusación. Si esto era correcto, el tribunal -al igual que el del juicio anteriordebía ahora emitir un veredicto condenatorio. En cambio, los jueces centraron el debate en el modo en que la prueba había sido obtenida:

Que, si bien es cierto estos sentenciadores han arribado a la convicción de que efectivamente ha existido un delito y que en este le cupo participación al acusado, no es menos que por mandato legal están obligados a examinar la prueba con tal rigurosidad que no quede duda razonable alguna respecto a su licitud, suficiencia y credibilidad y, frente a este trascendental principio de seguridad jurídica su labor -al momento de valorarla- debe centrarse en dos aspectos relevantes:

$1^{\circ}$.- que la prueba que se incorpora a juicio se haya obtenido sin vulnerar garantías fundamentales que se encuentran consagradas en nuestra Constitución Política de la República y en los Tratados Internacionales suscritos por el Estado de Chile y que, por mandato de la misma Constitución nos obligan; y,

$2^{\circ}$.- que esa prueba alcance los estándares de convicción exigidos para dar por acreditado un hecho punible ${ }^{38}$.

\footnotetext{
36 Séptimo Tribunal de Juicio Oral en lo Penal de Santiago, rol № 148-2006, de 1 de enero de 2007, considerando noveno.

37 Corte Suprema, rol № 678-2007, de 6 de junio de 2007, considerando sexto.

38 Séptimo Tribunal de Juicio Oral en lo Penal de Santiago, rol № 148-2006, de 9 de julio de 2007, considerando octavo. Es interesante notar que para el tribunal la licitud de la prueba debe ser probada más allá de toda duda razonable. Una pretensión como esta solo puede fundarse en consideraciones distributivas: los tribunales pretenden otorgar una ventaja al acusado que haga más probable que de
} 
Entendiendo que ambas labores constituían parte de su función, el tribunal comenzó un análisis de los hechos relevantes para la configuración de la infracción de garantías fundamentales.

En primer lugar, se consideró que existía una orden de detención emanada de un Juez del Crimen competente, que ordenaba la detención del acusado a fin de notificarle una sentencia por quebrantamiento de condena. Dicha orden consignaba dos domicilios (el de la madre del acusado y el del propio acusado), facultando a los funcionarios policiales para allanar y descerrajar ambos. Así, la policía detuvo al acusado frente al primer domicilio (el de su madre), y luego, dos de los funcionarios (que declararon en juicio) concurrieron con el acusado hasta su propio domicilio. Los policías ingresaron a dicho lugar en compañía del acusado, y encontraron una planta de marihuana en el patio trasero. Al consultarle al acusado si se encontraba cometiendo algún otro delito, este respondió que tenía un arma de fuego en su dormitorio principal, bajo la almohada.

Como los hechos descritos hasta aquí (aunque necesarios para la configuración de la infracción y no controvertidos en el debate) no son suficientes para afirmar la vulneración de garantías, el tribunal dio un paso adicional: indicó que la orden judicial tenía por objeto solo la detención del imputado, agotándose una vez realizada por la policía frente al primer domicilio. Así, a juicio del tribunal, a pesar de encontrarse consignado el segundo domicilio en la orden y de haberse facultado a la policía para allanar y descerrajar, luego de aprehendido el imputado ya no existía autorización para dichas actuaciones:

Que, conforme a lo declarado por los tres funcionarios policiales el acusado fue detenido en la calle, en las afueras del domicilio de su madre, por lo que, en consecuencia, con esta detención, se cumplió, se agotó, la orden que se les endosó, siendo innecesario constituirse en los otros domicilios bajo el pretexto de corroborar el domicilio real del acusado.

[...] los funcionarios aprehensores sólo tenían una orden que los facultaba para detener y poner a disposición del Tribunal al acusado y, para el evento de que no fuere habido, y se tuviere conocimiento de que se encontraba en uno de dichos domicilios, se facultaba el ingreso y allanamiento. En consecuencia, la actuación de la policía para obtener la prueba con la que se pretendió acreditar el hecho punible por el cual el Ministerio Público acusó, fue obtenida con

cometerse un error en la decisión, este favorezca una falsa absolución (y no una falsa condena). Sin embargo, insistir ciegamente en la adopción de prácticas fundadas en este tipo de consideraciones ignora no solo la actitud social frente al costo de los errores sino también la tasa global de errores que el sistema procesal penal produce. Para la profundización de estas cuestiones puede verse LaUDAN (2006), pp. 124 y ss. 
vulneración de garantías fundamentales, como también vulnerando principios establecido en el Código Procesal Penal ${ }^{39}$.

Más aún, el tribunal agregó que el ingreso al domicilio no fue autorizado por el acusado, conclusión a la que llegó en virtud de la declaración de este último en el juicio y a pesar de encontrarse en contradicción con las declaraciones de los tres funcionarios policiales. De esta forma, al no haberse cumplido -en opinión del tribunal- ninguno de los supuestos que permitían la entrada y registro de un lugar cerrado, el ingreso de los policías al domicilio del acusado habría vulnerado el derecho fundamental de la inviolabilidad del hogar. Y siendo dicha garantía parte del debido proceso, también este habría sido infringido.

En base a estas consideraciones, el tribunal concluyó que no podía otorgarle ningún valor a la prueba material presentada por la acusación (i.e. el arma de fuego y las municiones) por haber sido obtenida con vulneración de garantías fundamentales, como tampoco a todas las demás pruebas obtenidas como consecuencia de ella (i.e. las declaraciones de los policías, las declaraciones de los peritos, y los oficios emitidos por la Dirección General de Movilización Nacional). En palabras del propio tribunal:

Que, frente a la vulneración evidente de garantías constitucionales en el procedimiento llevado a cabo por la policía, estos sentenciadores no pueden otorgarle ningún valor probatorio a la prueba incorporada por el órgano persecutor, encontrando sustento esta decisión en la doctrina de "los frutos del árbol envenenado", en cuanto resulta imposible utilizar como prueba en un proceso penal elementos de convicción obtenidos mediante la violación de garantías, cuyo es el caso de marras ${ }^{40}$.

Y, evidentemente, una vez desechada dichas pruebas, la hipótesis acusatoria resultaba insuficientemente acreditada (a pesar de haber admitido en un principio que la consideración de todas las pruebas rendidas en el juicio producía la convicción respecto de la existencia del delito):

Que, descartada la prueba del órgano persecutor, sólo queda como pieza de convicción en contra del acusado su confesión, y no pudiéndosele condenar solo con ella, conforme lo dispone el inciso final del artículo 340 del Código Procesal Penal, deberá absolvérsele del cargo formulado por el Ministerio Público, como autor de delito de tenencia ilegal de arma de fuego, ocurrido en la comuna de La Florida ${ }^{41}$.

\footnotetext{
39 Séptimo Tribunal de Juicio Oral en lo Penal de Santiago, rol № 148-2006, de 9 de julio de 2007, considerando décimo segundo.

40 Séptimo Tribunal de Juicio Oral en lo Penal de Santiago, rol No 148-2006, de 9 de julio de 2007, considerando décimo quinto.

41 Séptimo Tribunal de Juicio Oral en lo Penal de Santiago, rol № 148-2006, de 9 de julio de 2007, considerando décimo quinto.
} 
La exposición de todas estas consideraciones no es trivial. Lo que interesa mostrar es que, enfrentados al caso, los tribunales determinan que los derechos fundamentales del imputado efectivamente han sido afectados incluso si el camino no parece tan evidente ${ }^{42}$. Esto tal vez no sería problemático si la consecuencia no fuese la exclusión de la prueba obtenida. Pero, en cambio, lo que está en juego es precisamente dicha supresión.

Antes de continuar, detengámonos un momento en el lenguaje utilizado por los tribunales. Recordemos que el tribunal del tercer juicio señalaba "que, frente a la vulneración evidente de garantías constitucionales [...], estos sentenciadores no pueden otorgarle ningún valor probatorio a la prueba incorporada por el órgano persecutor [...], en cuanto resulta imposible utilizar como prueba en un proceso penal elementos de convicción obtenidos mediante la violación de garantías, cuyo es el caso de marras. Que, descartada la prueba del órgano persecutor, sólo queda como pieza de convicción en contra del acusado su confesión [...]" $]^{\prime 43}$.

Este no constituye una particularidad del caso en cuestión. Resolviendo sobre un delito de tráfico de drogas, por ejemplo, el Tribunal de Juicio Oral en lo Penal de Curicó indicó que "el fenómeno de la prueba ilícita no solo puede ser enfocado como un problema de admisibilidad de la prueba, sino también como un problema de valoración o, en términos más generales, de inutilizabilidad o ineficacia de la prueba obtenida ilícitamente" ${ }^{\prime 4}$.

Lo que ambos fallos tienen en común es que evitan referirse explícitamente a la actividad realizada por el tribunal como "exclusión probatoria", y en cambio, la sostienen como parte de la valoración. La razón es que existen poderosos argumentos (jurídicos y no jurídicos) en contra de que los tribunales de juicio oral en lo penal excluyan prueba (que ya ha sido admitida por otro tribunal de igual jerarquía), de los que los jueces deben hacerse cargo si han de aceptar y promover dicha exclusión en el juicio oral. Por el contrario, si esta actividad constituyese en realidad parte de la valoración de la prueba, los tribunales de juicio oral serían indiscutiblemente competentes para llevarla a cabo.

$\mathrm{Y}$, sin embargo, la utilización de expresiones como "no otorgarle ningún valor probatorio", "inutilizar", "descartar" o "hacer ineficaz", no constituye más que un absurdo intento de ignorar el problema. Como veremos, la valoración

\footnotetext{
${ }^{42}$ Probablemente ello deriva del loable interés en proteger a las personas sujetas a un procedimiento penal.

43 Séptimo Tribunal de Juicio Oral en lo Penal de Santiago, rol № 148-2006, de 9 de julio de 2007, considerando decimoquinto.

44 Sentencia del Tribunal de Juicio Oral en lo Penal de Curicó, rol № 25-2006, de 1 de julio de 2006, considerando decimosegundo.
} 
negativa de la prueba solo encuentra sentido si es entendida como una especie de exclusión de la prueba ilícita.

Pero no son únicamente los tribunales de instancia los que omiten tratar el asunto en los términos apropiados. Es basta la jurisprudencia de los tribunales superiores que apoya dicha posición, y que de hecho, sostiene una diferencia entre la exclusión de la prueba y su valoración negativa.

\section{La "valoración negativa" en la Corte Suprema}

Comenzaremos con el tráfico de drogas resuelto por el Tribunal de Juicio Oral en lo Penal de Curicó al que nos referimos en la sección anterior. En dicho caso, el acusado fue absuelto porque, a juicio del tribunal, una vez descartadas las pruebas obtenidas mediante la vulneración de derechos fundamentales, no existía prueba suficiente para emitir un veredicto condenatorio ${ }^{45}$. En consecuencia, la acusación interpuso un recurso de nulidad fundado, inter alia, en que el tribunal de juicio oral habría omitido valorar los medios de prueba de manera conforme con el artículo 297 del Código Procesal Penal ${ }^{46}$. Dicha causal fue desestimada por la Corte Suprema bajo los siguientes argumentos:

[E]l examen del fallo recurrido demuestra evidentemente que dicha resolución cumple a cabalidad con las exigencias anotadas [i.e. la valoración de la prueba conforme al artículo 297], desde que se ha hecho cargo circunstanciada y razonadamente, con los debidos fundamentos, tanto de los aspectos de hecho como de derecho y doctrinarios que se estimaron aplicables al caso, para desestimar o restar valor a la prueba de cargos aportada y producida en la audiencia del juicio por el Ministerio Público en razón de su ilicitud, ello como consecuencia de una valoración negativa de la misma, en mérito de lo cual se absolvió al acusado por falta de acreditación de los cargos formulados en su contra ${ }^{47}$.

[E]l tribunal [...] procedió a restarle mérito o valor probatorio, situación que como se dijo, satisface las exigencias de fundamentación del fallo y no puede ser considerada como lo pretende el recurrente, un acto de exclusión de la misma $[\ldots]^{48}$.

\footnotetext{
45 Sentencia del Tribunal de Juicio Oral en lo Penal de Curicó, rol № 25-2006, de 1 de julio de 2006, considerando decimocuarto.

46 La exposición completa de las causales invocadas por la fiscalía puede verse en Corte Suprema, rol № 3570-2006, de 20 de septiembre de 2006, considerandos primero, segundo, tercero y cuarto. La causal en cuestión se encuentra configurada por el artículo 374 letra e) del Código Procesal Penal en relación al artículo 342 letra c) y al artículo 297 del mismo código.

47 Corte Suprema, rol № 3570-2006, de 20 de septiembre de 2006, considerando decimocuarto. Los paréntesis son míos.

48 Corte Suprema, rol №3570-2006, de 20 de septiembre de 2006, considerando decimoquinto. Los paréntesis son míos.
} 
$[R]$ estar valor probatorio a la prueba rendida en la audiencia, no puede significar en caso alguno, que se desconoce la decisión del Tribunal de Garantía consignada en el auto de apertura, desde que ésta, si bien fija los medios de prueba a rendir en la audiencia del juicio oral, su valoración en miras a la decisión de la controversia, es atribución privativa de los sentenciadores Ilamados por ley a resolverla, esto es, los Jueces del Tribunal del Juicio Oral respectivo ${ }^{49}$.

Como es evidente, el esfuerzo de la Corte Suprema se concentra en presentar la desestimación de la prueba como una actividad que forma parte del proceso de valoración, conforme al artículo 297 del Código Procesal Penal ${ }^{50}$. La Corte es de hecho explícita: dicha actividad no puede ser considerada un acto de exclusión probatoria, y, en cambio, forma parte de una valoración "en miras a la decisión de la controversia". De esta forma, ella constituiría una atribución privativa del tribunal de juicio oral en lo penal.

Pero es que en casos recientes, la Corte Suprema ha ido incluso más lejos. Ahora, la "valoración negativa de la prueba" ya no es concebida como una mera "atribución", sino como un deber de los jueces de fondo. Así, en un caso de robo en bienes nacionales de uso público en que el autor fue condenado por el Juzgado de Garantía de Valparaíso, la Corte, luego de estimar que la prueba fue obtenida con infracción de garantías fundamentales, declaró:

El cumplimiento de la ley y el respeto a los derechos garantizados por la Constitución Política de la República no conforman aquello que los jueces están Ilamados a apreciar libremente, sino que configuran presupuestos de legitimidad para la emisión de cualquier pronunciamiento sobre el caso sometido a su consideración ${ }^{51}$.

Así, entonces [...] al haber sido declarada ilegal la detención por una actuación funcionaria que violó normas precisas y determinadas que regulaban el actuar policial, la ilicitud se extiende a todos los resultados generados cabalmente por ella, lo que en el caso de autos importaba extender la exclusión por valoración negativa de la prueba producida en la audiencia respectiva ${ }^{52}$.

\footnotetext{
49 Corte Suprema, rol № 3570-2006, de 20 de septiembre de 2006, considerando decimosexto. Los paréntesis son míos.

50 En este punto es útil precisar que utilizo el término desestimación para referirme a la renuncia por parte del juzgador de los hechos a determinar el grado de soporte o apoyo inductivo que una prueba determinada otorga a las hipótesis relevantes. En otras palabras, no se trata de que el decisor valore la prueba y descubra que ella no cumple la función que la parte que la presentó inicialmente le atribuía, sino de que (como veremos con mayor profundidad más adelante), la prueba derechamente no es valorada. Agradezco las observaciones de un revisor anónimo a este respecto.

51 Corte Suprema, rol № 23683-2014, de 22 de octubre de 2014, considerando séptimo. La Corte ya se había pronunciado exactamente en el mismo sentido (y con las mismas palabras) en Corte Suprema, rol № 3828-2014, de 16 de abril de 2014, considerando duodécimo.

52 Corte Suprema, rol № 23683-2014, de 22 de octubre de 2014, considerando octavo. Los paréntesis son míos.
} 
Dejémonos de rodeos. No importa qué digan los tribunales que están haciendo cuando "valoran negativamente" la prueba, sino lo que realmente hacen. El caso examinado en la sección anterior es particularmente ilustrativo: Jueces que de un conjunto inicial de pruebas " $\mathrm{X}$ " (conformado por las pruebas $\mathrm{a}, \mathrm{b}$, c y d) consideran explícitamente que la culpabilidad del acusado ha resultado probada más allá de toda duda razonable, luego de desestimar, inutilizar o valorar negativamente algunas de las pruebas consideran que la hipótesis acusatoria resulta insuficientemente probada (sobre la base de un conjunto distinto de pruebas " $Y$ " conformado solo por las pruebas restantes).

La exclusión probatoria consiste en la supresión -por diversas razones- del conjunto de pruebas sobre el cual se adoptará la decisión sobre los hechos, de un elemento de juicio determinado y en principio disponible. Dado que la conformación del conjunto probatorio no se agota con la declaración de admisibilidad de las pruebas realizada en una audiencia preliminar, y, en cambio, incluye también la práctica de la prueba, e incluso su percepción por el tribunal, cualquier acto de desestimación que tenga como consecuencia que una o más pruebas determinadas no formen parte del conjunto definitivo constituye, por definición, un acto de exclusión probatoria. Decir que la "valoración negativa" no lo es, en el mejor de los casos, revela una incomprensión por parte de los jueces respecto de cómo funciona el razonamiento probatorio en el Derecho y de cómo debe concebirse la prueba si su finalidad principal es maximizar la probabilidad de obtener decisiones correctas.

La razón por la que los tribunales sostienen el asunto en estos términos es que ello permitiría presentar la supresión de la prueba como parte de su valoración, la que -a diferencia de la exclusión probatoria- indudablemente es de competencia de los tribunales del juicio oral en lo penal. El razonamiento parece ser el siguiente:

(1) Una valoración de la prueba jurídicamente correcta es aquella que se realiza conforme al artículo 297 del Código Procesal Penal.

(2) La "valoración negativa" de la prueba obtenida en forma ilícita no contradice los principios de la lógica, las máximas de la experiencia, ni los conocimientos científicamente afianzados.

(3) La exposición de las razones para haber considerado la prueba como ilícita y haberla "valorado negativamente" es, precisamente, hacerse cargo de la prueba desestimada.

(4) La indicación de las pruebas supervivientes en que se funda la decisión de dar por probados -o no probados- los hechos, constituye el señalamiento de los medios de prueba por los que se acreditan los hechos probados de una forma que permite la reproducción del razonamiento.

(5) Por lo tanto, la valoración negativa, cuando se han expuesto las razones para la desestimación y se han señalado los medios de prueba restantes sobre los que se ha adoptado la decisión, es una valoración jurídicamente correcta. 
Mediante esta forma de entender la exclusión probatoria por parte de los tribunales de juicio oral en lo penal, no solo se desvirtúa la valoración de la prueba, sino que se contribuye a la confusión existente en la teoría y práctica de la actividad probatoria en el Derecho. La valoración de la prueba ya no constituiría la actividad del juez con el objeto de determinar el grado de apoyo o refutación que un determinado conjunto probatorio otorga a las hipótesis jurídicamente relevantes, sino que incluiría el examen de diversas cuestiones que harían que las pruebas fueran indeseables.

$Y$, sin embargo, esta posición ignora que lo único intrínseco a las mismas pruebas que puede ser valorado es precisamente el grado en que corroboran o refutan las proposiciones fácticas. En efecto, cuando un tribunal "valora negativamente" una prueba ilícita no está valorando una característica intrínseca a la prueba, sino el medio a través del cual fue obtenida. Esto, que parece tan obvio, es perdido de vista por los tribunales.

En el caso expuesto en la sección anterior, el arma de fuego y la declaración de los peritos fueron "valoradas negativamente". Dichas pruebas, en realidad, no adolecían de ningún defecto intrínseco que obligara al tribunal a tener la hipótesis acusatoria como refutada (o, al menos, como insuficientemente probada). Es más, si esas mismas pruebas hubiesen sido obtenidas de forma distinta, a pesar de ser su contenido exactamente el mismo, el tribunal las habría "valorado positivamente" (de hecho, el tribunal admite que ellas corroboraban la hipótesis acusatoria en un grado que permitía superar el estándar de prueba aplicable). En consecuencia, lo que el tribunal realmente efectúa es un examen de los hechos que constituyen el procedimiento a través del cual la prueba se obtuvo, valorando dichos hechos negativa o positivamente (según si mediante ellos se vulneraron derechos fundamentales o no), para luego excluir del conjunto sobre el cual se adoptará la decisión la prueba obtenida como resultado de los hechos valorados de la primera forma.

Antes de continuar, debemos detenernos para realizar ciertas precisiones. En realidad, dentro del conjunto de actividades que el tribunal ejecuta cuando "valora negativamente" es posible encontrar ciertos actos que constituyen propiamente una valoración. Imaginemos que, en el caso descrito, un sujeto " $M$ " ha visto a los funcionarios policiales ingresar al domicilio del imputado sin el consentimiento del propietario o del encargado y sin existir signos de que se estuviera cometiendo un delito en el interior. Es más, imaginemos que así lo declara en el juicio oral. Con el objeto de establecer si efectivamente existió una vulneración de los derechos del imputado, dicha prueba será valorada determinando el grado de apoyo o corroboración que le otorga a la hipótesis de la vulneración. Si ese fuere el caso, el tribunal se encontraría propiamente determinando el valor de la prueba. Es más, lo estaría haciendo en una forma racional (estableciendo la existencia -o inexistencia- de relaciones inferenciales 
entre la prueba aportada y la proposición). Y sin embargo, sería el testimonio del sujeto " $\mathrm{M}$ " el que estaría siendo valorado y no la prueba obtenida a consecuencia del registro efectuado por los funcionarios policiales. Esto pone de relieve que, en estos casos, si es posible encontrar propiamente una valoración de la prueba, ello será a costa de modificar la proposición fáctica objeto de la actividad probatoria: ya no se trataría de probar la ocurrencia de los hechos operativos de la norma jurídica penal, sino de probar los hechos constitutivos de la infracción de derechos fundamentales.

Las consideraciones ya transcritas de la Corte Suprema son especialmente clarificadoras respecto de la verdadera naturaleza de la "valoración negativa":

Así, entonces [...] en el caso de autos importaba extender la exclusión por valoración negativa de la prueba producida en la audiencia respectiva ${ }^{53}$.

La Corte revela, probablemente en forma involuntaria, que dicha actividad constituye propiamente una exclusión. Y lo cierto es que esta constituye la única posición conceptualmente sostenible.

\section{La exclusión de prueba por los Tribunales de Juicio Oral en lo Penal}

Se ha dicho que desde una perspectiva racionalista, entonces, cualquier acto de desprecio de la prueba ofrecida que impida que ella sea considerada para la decisión, constituye un acto de exclusión probatoria ${ }^{54}$. Y sin embargo, ello nada dice todavía respecto de la posibilidad de excluir prueba en el juicio oral.

Existen diversas razones que impiden considerar que el Derecho permite a los tribunales de juicio oral en lo penal excluir prueba del conjunto sobre el cual deberán adoptar la decisión de los hechos. La primera se refiere a la organización jerárquica de los tribunales en nuestro país y a la forma en que las resoluciones judiciales pueden ser impugnadas. Dado que la exclusión de prueba por haberse obtenido con infracción de derechos fundamentales es decidida por medio de una resolución judicial, dictada por el juez de garantía (denominada en Chile como "auto de apertura del juicio oral"), y dado que las resoluciones judiciales solo pueden ser modificadas por el mismo tribunal que las dictó o por su superior jerárquico (y mediante los medios de impugnación

\footnotetext{
53 Corte Suprema, rol No 23683-2014, de 22 de octubre de 2014, considerando octavo. Los paréntesis son míos.

54 La adherencia a una concepción subjetivista de la prueba tampoco permite justificar una noción como la "valoración negativa". Más aún, dado que los estados mentales requeridos para la prueba de una proposición son el resultado de todos los factores (racionales e irracionales) susceptibles de incidir, bajo dicha concepción ni siquiera tendría sentido hablar de inutilizabilidad, ineficacia o, incluso, exclusión, una vez que la práctica de la prueba ha sido presenciada por el tribunal.
} 
expresamente previstos por la ley), el tribunal de juicio oral no podría modificar la decisión sobre qué pruebas deben ser excluidas del conjunto a considerar para determinar los hechos del caso. La razón es que estos tribunales no constituyen superiores jerárquicos de los jueces de garantía, ni han sido creados para revisar y modificar sus decisiones ${ }^{55}$.

Como es evidente, todo el peso del argumento descansa sobre la posibilidad de responder positivamente a la siguiente pregunta: ¿Es realmente la "valoración negativa" una forma de revisión de la exclusión probatoria resuelta por el juez de garantía? O, desde otra perspectiva: ¿es el asunto decidido mediante una "valoración negativa" - o al menos parte de él- el mismo que ya ha sido decidido por el juez de garantía en el auto de apertura? De hecho, el esfuerzo de los tribunales por construir una tesis fundada en la valoración del artículo 297 del Código Procesal Penal apunta precisamente a responder negativamente a esta pregunta: si la valoración negativa no constituye una forma de exclusión, el tribunal de juicio oral no estaría revisando y modificando una resolución dictada por un tribunal de igual jerarquía (sin ser competente para ello).

Examinemos, entonces, si ambas actuaciones judiciales deciden un mismo asunto o no. Para ello es útil recurrir a los elementos de la cosa juzgada, ya que ellos permiten precisamente determinar cuándo un asunto sometido al conocimiento de un tribunal es en realidad el mismo que otro ya resuelto. La doctrina tradicional ha indicado que entre ambas cuestiones debe darse una triple identidad: identidad de los sujetos, identidad del objeto pedido e identidad de la causa de pedir ${ }^{56}$.

Respecto de los sujetos no es posible cuestionar la existencia de identidad: tanto en la audiencia de preparación del juicio oral como en el juicio oral mismo actúa el mismo acusador (normalmente la fiscalía) contra el mismo acusado. Respecto de la causa de pedir, tradicionalmente entendida como "la razón de la pretensión o sea el fundamento inmediato del derecho deducido en juicio ${ }^{\prime \prime 57}$, ella está constituida por la utilización de medios de investigación que han vulnerado los derechos fundamentales del acusado, tanto en la exclusión de la prueba ilícita como en la "valoración negativa". Hasta aquí, no existiría controversia.

Es por ello que, si la tesis jurisprudencial es plausible, debe sostener la distinción entre uno y otro asunto respecto del objeto o "bien jurídico disputado"

55 Tavolari (2003), pp. 153 y ss.

56 Al respecto puede verse Couture (2007), pp. 337 y ss.

57 Couture (2007), p. 354.

58 Para la definición de objeto como elemento de la cosa juzgada véase Couture (2007), p. 352. 
Así, en una actuación se pretendería que la prueba no sea practicada en el juicio oral, y en la otra, que, a pesar de haber sido practicada, su resultado no sea considerado para la determinación de los hechos en la sentencia.

En efecto, esta diferenciación es posible. El problema consiste, más bien, en que ella es irrelevante: solo se refiere al momento en que la exclusión es realizada y no a la naturaleza de la actividad. En uno y otro caso se trata, en realidad, de que ciertos elementos de prueba no formen parte del conjunto sobre el cual se adoptará la decisión.

Una de las causas, tal vez, de que los tribunales entiendan que la exclusión solo puede tener por objeto evitar la práctica de las pruebas, pudiendo así tener lugar únicamente antes de su rendición (otorgando a todo lo que pudiese realizarse con posterioridad -como la "valoración negativa"- una naturaleza distinta), la constituye la predominancia de la concepción subjetivista de la prueba y la importancia desmedida que le otorga al principio de inmediación ${ }^{59}$. Si, en efecto, aceptamos que el criterio para decidir sobre los hechos es el estado psicológico o mental del juzgador, una vez percibida la prueba por los jueces será obviamente imposible imaginar su exclusión (ella ya se ha convertido, de manera irreversible, en un factor más que ha incidido en el proceso cognitivo).

En consecuencia, en etapas posteriores a la práctica de la prueba solo sería posible "valorarla negativamente". Y sería favorable a esta lectura el lenguaje utilizado por el Código Procesal Penal en sus artículos 276 y 277: ellos señalan que el juez excluirá ciertas pruebas de "ser rendidas en el juicio oral" y que indicará las restantes "que deberán rendirse en el juicio oral". Así, pareciera ser que lo que está en juego en la exclusión probatoria es solo la posibilidad de que la prueba sea rendida. En cambio, una vez practicada, la decisión de considerarla o no para la decisión final es una cuestión completamente distinta.

Para decirlo sin rodeos, esta interpretación es absurda. En primer lugar, porque el artículo 297 del Código Procesal Penal obliga al tribunal de juicio oral a valorar toda la prueba producida, de manera que cuando el juez de garantía admite una prueba para "ser rendida en el juicio oral", la admite para ser valorada y considerada en la adopción de la decisión sobre los hechos.

En segundo lugar, porque una vez entendido (como la concepción racionalista señala enfáticamente) que el conjunto probatorio solo termina de conformarse finalizada la práctica de las pruebas, es posible comprender que el que una actuación judicial constituya un acto de exclusión no depende del momento en que se realice, sino de que suprima ciertos elementos del acervo definitivo sobre el cual se adoptará la decisión. La exclusión es perfectamente posible con posterioridad a que las pruebas sean rendidas (aunque no contemplada

59 Sobre la primera puede verse ACCATINO (2006), pp. 18 y ss. 
por el Derecho y epistemológicamente indeseable). Así, cuando un tribunal de juicio oral en lo penal "valora negativamente la prueba" se pronuncia en realidad sobre un asunto que ya ha sido resuelto por el juez de garantía (existiendo identidad del bien jurídico sin importar que este sea disputado en dos momentos distintos) ${ }^{60}$.

La conclusión es que existe triple identidad entre ambas cuestiones: la "valoración negativa" constituye una revisión y modificación del auto de apertura de juicio oral, al menos en la parte en que este último se refiere a la prueba admitida al juicio. Y, recordemos, los tribunales de juicio oral en lo penal no constituyen superiores jerárquicos de los jueces de garantía ni han sido creados para revisar sus decisiones.

El segundo argumento que puede formularse también depende de los elementos de la cosa juzgada, y puede ser reconstruido de la siguiente forma ${ }^{61}$ :

(1) La cosa juzgada convierte a una resolución judicial en irrevocable e inimpugnable.

(2) Las sentencias interlocutorias firmes producen efecto de cosa juzgada, conforme al artículo 175 del Código de Procedimiento Civil.

(3) Una resolución judicial es una sentencia interlocutoria, entre otras, cuando resuelve sobre algún trámite que debe servir de base en el pronunciamiento de una sentencia definitiva, conforme al artículo 158 del Código de Procedimiento Civil.

(4) El auto de apertura del juicio oral resuelve sobre un trámite que debe servir de base para el pronunciamiento de una sentencia definitiva penal (ya que determina la prueba que deberá ser considerada por el tribunal de juicio oral para decidir sobre los hechos).

(5) El auto de apertura del juicio oral es una sentencia interlocutoria, por lo que una vez firme, produce el efecto de cosa juzgada, siendo irrevocable e inimpugnable.

$\mathrm{Si}$, como es posible apreciar, la producción del efecto de cosa juzgada depende de que la resolución se encuentre firme, la idoneidad del argumento estribará en que el auto de apertura esté ejecutoriado con anterioridad a que la prueba sea "valorada negativamente". Al respecto, el artículo 281 del Código Procesal Penal determina explícitamente que la etapa del procedimiento ante el tribunal de juicio oral en lo penal solo tenga inicio una vez que el auto de

\footnotetext{
60 Existe, por supuesto, la posibilidad de que la ilicitud surja como consecuencia de la práctica de la prueba en juicio. Si este es el caso, lo que estaría en juego es un asunto que no ha sido decidido por el juez de garantía y por tanto, el argumento no sería pertinente. Debo esta aclaración a las observaciones de un revisor anónimo. Sin embargo, todavía existen otros argumentos jurídicos y extra-jurídicos para oponerse a la exclusión probatoria por el tribunal de juicio oral.
}

61 En términos similares Tavolari (2003), p. 157. 
apertura se encuentre firme. En tanto no lo esté, este no será remitido por el juez de garantía. La consecuencia es obvia: la "valoración negativa" de la prueba solo podrá tener lugar, en todo evento, una vez firme el auto de apertura del juicio oral. Y, sin embargo, en este punto la resolución es ya inimpugnable e irrevocable.

Existe un tercer argumento que dice relación con la historia fidedigna del establecimiento del inciso penúltimo del artículo 277 del Código Procesal Penal respecto de la forma de impugnar lo resuelto por el juez de garantía en el auto de apertura del juicio oral. A diferencia de la redacción vigente, el proyecto de Código Procesal Penal presentado por el Poder Ejecutivo negaba expresamente la posibilidad de que dicha resolución fuera recurrible. Dicho punto fue motivo de discusión en el Senado, donde la Comisión de Constitución, Legislación, Justicia y Reglamento indicó:

Causó preocupación en la Comisión la norma contenida en el inciso segundo, que permite al juez rechazar pruebas, sin que esta resolución pueda ser apelable, lo que podría significar dejar a una de las partes en la indefensión antes de empezar el juicio, especialmente en lo que dice relación con la prueba ilícita y aquellas que puedan estimarse dilatorias, porque van a quedar entregadas al criterio del juez de garantía sin revisión posterior.

Entendió que el propósito obedece a que esta audiencia debe fijar el contenido del juicio oral, y precisamente se trata de evitar que el tribunal oral tome conocimiento de pruebas que no pueden ser utilizadas y pueda formarse un prejuicio, especialmente de las pruebas obtenidas por medios ilícitos, así como que un sistema de recursos demasiado amplio podría significar la paralización del proceso, porque todos apelarían ante cualquier prueba que se les suprima.

Por ello, acordó establecer un recurso a favor sólo del fiscal para apelar ante la Corte de Apelaciones contra el rechazo de pruebas que provengan de diligencias declaradas nulas o hayan sido obtenidas con inobservancia de las garantías fundamentales. De esta forma se evita que el tribunal oral tome conocimiento de estas pruebas y se forme un juicio con elementos que no podrá después valorar. El recurso se concede en ambos efectos. Lo anterior no obsta a que las partes deduzcan por esta causa el recurso de nulidad contra la sentencia definitiva dictada en el juicio oral, si ello procediere de acuerdo a las reglas generales ${ }^{62}$.

En consecuencia, habiendo considerado la posibilidad de que el auto de apertura del juicio oral fuera impugnado, el legislador decidió que ello solo pudiera hacerlo la parte acusadora y a través del recurso de apelación. Entiéndase bien, no se trata de que involuntariamente se haya omitido señalar otros medios

${ }^{62}$ Véase la historia del establecimiento de la Ley Nº 19.696. Informe de la quinta sesión de la Comisión de Constitución, Legislación, Justicia y Reglamento del Senado. Las cursivas son mías. 
de revisión y modificación de lo resuelto, sino de que ellos expresamente han sido desechados. No podría, entonces, el tribunal de juicio oral en lo penal excluir prueba que ha sido admitida por el juez de garantía.

Existe, aún, un cuarto argumento que debe ser considerado. Este dice relación con la estricta legalidad de la competencia de los tribunales. Así lo expresa, entre nosotros, Raúl Tavolari:

Nunca resulta excesivo volver a destacar el régimen de estricta legalidad a la que se sujeta el tema de la competencia de los tribunales, legalidad reforzada por lo prevenido en los artículos $6^{\circ}$ y $7^{\circ}$ de la Constitución Política de la República y, en especial, por el artículo 108 del Código Orgánico de Tribunales, conforme al cual, la competencia es la facultad que tiene cada juez o tribunal para conocer de los negocios que la ley ha colocado dentro de la esfera de sus atribuciones [...].

Como sea, por la indiscutida militancia de este terreno -atribuciones de los Tribunales de Justicia- en el campo del derecho público, es fácil concluir que no pueden estos órganos públicos asumir otras atribuciones que aquellas que expresamente se les han conferido por ley ${ }^{63}$.

Este es, a mi juicio, el argumento más importante. Los tribunales solo pueden actuar conforme a las facultades que el ordenamiento jurídico les otorga; todo lo demás les está prohibido. De esta forma, lo importante será determinar si el sistema jurídico confiere a los tribunales de juicio oral en lo penal competencia para excluir prueba cuando ha sido obtenida con vulneración de derechos fundamentales.

En cierto sentido, los tres argumentos antes expuestos constituyen una respuesta negativa a esta pregunta: Que el tribunal de juicio oral en lo penal no sea el superior jerárquico del juez de garantía, que la resolución que se pronuncia sobre la exclusión de prueba tenga efecto de cosa juzgada y por tanto sea inimpugnable e inmutable, y que el legislador haya desechado -por distintas razones- la procedencia de otros recursos en contra de ella, dificulta en un grado considerable entender que dicha facultad fluye de una interpretación sistemática del ordenamiento jurídico. Pero lo que ahora interesa es la consideración de que, aun ignorando la existencia de dichos argumentos, es necesario que la ley confiera expresamente una facultad si su ejercicio ha de ser considerado una actuación válida de los tribunales.

En relación a ello, el artículo 18 del Código Orgánico de Tribunales determina la competencia de los tribunales de juicio oral en lo penal, y no contiene la exclusión de prueba ilícita entre sus facultades (mientras el artículo 14 del mismo cuerpo legal, que establece la competencia de los jueces de garantía,

63 Tavolari (2003), p. 155. 
expresamente les encomienda en su letra a) -isu primera letra!- asegurar los derechos del imputado y demás intervinientes en el proceso penal). Tampoco existe otra ley que le otorgue dicha competencia. De hecho, las normas del Código Procesal Penal que regulan la exclusión probatoria lo hacen refiriéndose explícitamente al juez de garantía, y a una instancia previa al juicio oral (i.e. la audiencia de preparación); respecto del tribunal de juicio oral en lo penal no se otorga facultad alguna ${ }^{64}$. La conclusión es evidente: Los tribunales de juicio oral en lo penal carecen de la facultad de excluir prueba ${ }^{65}$. En palabras de Tavolari:

En consecuencia, un tribunal de juicio oral, que abre debate sobre el rechazo de prueba ya aceptada por el juez de garantía, o sobre su licitud, previamente admitida por dicho juez o, finalmente sobre cualesquiera otra mención del auto, no sólo actúa fuera de su competencia, en términos jurídicamente inaceptables sino, además, vulnera la autoridad de cosa juzgada de que está revestido el mismo auto, por su condición de firme o ejecutoriado ${ }^{66}$.

En virtud de todas estas consideraciones, no parece posible afirmar que un tribunal de juicio oral en lo penal actúa correctamente (i.e. conforme al Derecho) cuando excluye prueba ilícita. Pero es que, además, esta es una práctica epistemológicamente indeseable. Dado que el tribunal deliberadamente disminuye la información sobre la cual adoptará su decisión, el riesgo cometer un error en la determinación de los hechos es considerablemente mayor (en la mayoría de los casos será a favor del imputado). Con este tipo de prácticas no solo se ignora la actitud social frente a los costos de los errores, sino que se eleva de manera irreflexiva el número global de errores que el sistema produce.

Por último (como si no fuese suficiente), en virtud de la "valoración negativa" un mismo tribunal se encuentra realizando funciones que responden a racionalidades distintas que rigen en distintos momentos procesales y que requieren la existencia de diferentes herramientas y dispositivos ${ }^{67}$. A diferencia de

64 De nuevo, la tesis de la "valoración negativa" fundada en el artículo 297 del Código Procesal Penal permitiría a los tribunales sortear esta dificultad (es la propia ley la que faculta a los tribunales de juicio oral a valorar la prueba). Pero, como ya hemos señalado, la "valoración negativa" no puede ser correctamente entendida como una forma de valoración.

65 Un argumento típico en contra de esta afirmación consiste en indicar que, sin importar cuáles son las facultades expresamente otorgadas a los tribunales, dicha atribución fluye de la Constitución y de los propios derechos fundamentales. El problema de este argumento es que pone en cuestión el principio de legalidad y la utilidad del artículo $7^{\circ}$ de la Constitución. Si es posible fundar atribuciones específicas de los órganos públicos directamente en los derechos fundamentales, ipor qué detenernos en la exclusión probatoria?

66 Tavolari (2003), p. 159; TAVolari (2005), p. 99.

67 En este sentido FerRer (2007), p. 68: "[La] clasificación en distintos momentos o fases de la actividad probatoria permite también una aplicación diferenciada de exigencias de racionalidad a cada uno de 
la audiencia de preparación, el juicio oral se encuentra técnicamente diseñado para la determinación de los hechos y no para la exclusión probatoria.

\section{Conclusión}

Recapitulando, en la primera sección hemos tratado dos nociones sobre la valoración de la prueba. Ellas tienen en común que conciben dicha actividad como el proceso de determinación de los hechos operativos de la norma sustantiva. Mientras que, con dicho objetivo, una valoración subjetiva examinará los estados mentales del juzgador de los hechos, una valoración racional buscará determinar el grado de apoyo inductivo que las pruebas otorgan a las proposiciones sobre hechos. Ninguna de las dos permite entender la "valoración negativa de la prueba" propiamente como una valoración.

Hemos dicho también que, dentro de ellas, la concepción racionalista es la que mejor da cuenta de los fines de la prueba en contextos jurídicos. Pero es que, además, la regulación expresa del Código Procesal Penal así parece requerirlo. En conformidad con ello, en la segunda sección hemos presentado uno de los métodos de corroboración de hipótesis desarrollados en el seno de la tradición racionalista con el objeto de arribar a soluciones correctas. La idea no ha sido sostener que el método de la inducción por eliminación sea infalible, el único posible o el más adecuado. En cambio, se ha utilizado para mostrar las características que tendría una actividad que fuese propiamente valorativa.

Así, en la tercera sección se ha aplicado dicho método a un caso en que los tribunales penales han "valorado negativamente la prueba". La conclusión ha sido que dicha actividad no constituye propiamente un tipo de valoración, y que, en cambio, conforme al lenguaje utilizado por la Corte Suprema en la sección cuarta, ella se ajusta naturalmente a las características de una exclusión probatoria.

La sección quinta, por último, ha tenido por objeto presentar las razones por las que los Tribunales de Juicio Oral en lo Penal no podrían excluir la prueba admitida al juicio. Y es que no solo dicha posibilidad no se encuentra contemplada por el Derecho (en circunstancias que los tribunales solo pueden actuar dentro de la esfera de sus competencias), sino que, además, existen razones epistemológicas y políticas para que la exclusión no tenga lugar durante el juicio oral.

Antes de finalizar es necesario precisar que las conclusiones a las que ha arribado la última sección son independientes del resto del trabajo. De esta forma, los partidarios de que la prueba obtenida bajo una supuesta infracción de

esos momentos. Dado que la actividad que en cada uno de ellos se realiza es sustancialmente distinta, también lo serán las exigencias que la racionalidad impone". 
derechos fundamentales sea desestimada en el juicio oral a pesar de haber sido admitida por el juez de garantía, deberán explicar bajo qué razones (jurídicas y de otra índole) los tribunales de juicio oral en lo penal estarían facultados para la exclusión si desean que esta práctica subsista. Y es que -y esta ha sido la idea principal del presente trabajo- el discurso de la "valoración negativa" es insostenible y solo contribuye a la confusión existente en nuestra cultura jurídica respecto del sentido de la prueba en los procesos judiciales. Si nuestro objetivo al diseñar reglas y prácticas procesales y probatorias es realmente maximizar la probabilidad de obtener soluciones correctas y, por tanto, justas, debemos comenzar por utilizar el lenguaje adecuado para identificar apropiadamente los problemas que nos aquejan.

\section{BIBLIOGRAFIA CITADA}

AcCatino, Daniela (2011): "Certezas, dudas y propuestas en torno al estándar de la prueba penal", en: Revista de Derecho de la Pontificia Universidad Católica de Valparaíso (No 37), pp. 483-511.

AcCatino, Daniela (2010): "El modelo legal de justificación de los enunciados probatorios en el proceso penal y su control a través del recurso de nulidad", en: Accatino, Daniela (Coord.) Formación y valoración de la prueba en el proceso penal (Santiago de Chile, Abeledo Perrot), pp. 119-143.

ACCATINO, Daniela (2006): "La fundamentación de la declaración de hechos probados en el nuevo proceso penal: un diagnóstico", en: Revista de Derecho de la Universidad Austral de Chile (vol. 19, № 2), pp. 9-26.

BLACK, Max (1984): Inducción y probabilidad (Madrid, Cátedra).

Cortez Matcovich, Gonzalo (2006): El Recurso de Nulidad: Doctrina y Jurisprudencia (Santiago de Chile, LexisNexis).

Couture, Eduardo J. (2007): Fundamentos del derecho procesal civil, Cuarta edición (Montevideo, Editorial B de F).

Del Río Ferrettı, Carlos (2012): "Estudio sobre el derecho al recurso en el proceso penal", en: Revista del Centro de Estudios Constitucionales (vol. 10, № 1), pp. 245-288.

DucE, Mauricio (2010): "Admisibilidad de la prueba pericial en juicios orales. Un modelo para armar en la jurisprudencia nacional", en: Accatino, Daniela (Coord.), Formación y valoración de la prueba en el proceso penal (Santiago de Chile, Abeledo Perrot), pp. 45-86.

Ferrer Beltrán, Jordi (2011): "Apuntes sobre el concepto de motivación de las decisiones judiciales", en: Isonomía: Revista de teoría y filosofía del Derecho (No 34), pp. 87-108. 
Ferrer Beltrán, Jordi (2010): "La prueba es libertad, pero no tanto. Una teoría de la prueba cuasi bethamiana", en: Accatino, Daniela (Coord.), Formación y valoración de la prueba en el proceso penal (Santiago de Chile, Abeledo Perrot), pp. 3-19.

FerRER BeLtRÁN, Jordi (2007): La valoración racional de la prueba (Madrid, Marcial Pons).

Ferrer Beltrán, Jordi (2005): Prueba y verdad en el derecho (Madrid, Marcial Pons).

Hempel, Carl G. (1999): Filosofía de la ciencia natural (Madrid, Alianza).

KING, Patricia (2000): "Internalismo, Externalismo y Autoconocimiento", en: Critica. Revista Hispanoamericana de Filosofía (vol. 32, № 96), pp. 99-119.

LAUDAN, Larry (2006): Truth, error, and criminal law: an essay in legal epistemology (Cambridge, Cambridge University Press).

LAUDAN, Larry (2005): "Por qué un estándar de prueba subjetivo y ambiguo no es un estándar", en: Doxa: Cuadernos de Filosofía del Derecho $\left(\mathrm{N}^{\circ} 28\right)$, pp. 95-113.

Maccormick, Neil (2000): "Razonabilidad y objetividad", en: Revista de Ciencias Sociales ( $\left.{ }^{\circ} 45\right)$, pp. 399-436.

Maturana Baeza, Javier (2014): Sana crítica: un sistema de valoración racional de la prueba (Santiago de Chile, Legal Publishing Chile).

Nieva Fenoll, Jordi (2012): "Oralidad e inmediación en la prueba: luces y sombras", en: Justicia: Revista de Derecho Procesal (№ 1), pp. 101-120.

Politoff, Sergio (2006): Lecciones de derecho penal chileno: parte especial, segunda edición (Santiago de Chile, Editorial Jurídica de Chile).

ReYes Molina, Sebastián (2012): "Presunción de inocencia y estándar de prueba en el proceso penal: Reflexiones sobre el caso chileno", en: Revista de Derecho de la Universidad Austral de Chile (vol. 25, № 2), pp. 229-247.

TAVOLARI, Raúl (2005): Instituciones del nuevo proceso penal: cuestiones y casos (Santiago de Chile, Editorial Jurídica de Chile).

Tavoları, Raúl (2003): "Informe en derecho: del debate sobre la licitud de la prueba y su exclusión por parte del tribunal de juicio oral y procedencia legal de consignar en la sentencia de juicio oral las decisiones relevantes adoptadas en la audiencia", en: Boletín del Ministerio Público ( $\left.\mathrm{N}^{\circ} 14\right)$, pp. 151-160.

TwINING, William (2006): Rethinking Evidence: Exploratory Essays, segunda edición (Cambridge, Cambridge University Press). 


\section{NORMAS CITADAS}

Constitución Política de la República de Chile.

Código Penal.

Código Procesal Penal.

Código de Procedimiento Civil.

Código Orgánico de Tribunales.

Ley $N^{\circ} 17.798$ de 1977 sobre control de armas.

\section{JURISPRUDENCIA CITADA}

Corte Suprema, de 22 de octubre de 2014, rol № 23683-2014 (Acción de Nulidad).

Corte Suprema, de 16 de abril de 2014, rol № 3828-2014 (Acción de Nulidad).

Corte Suprema, de 20 de febrero de 2014, rol № 65-2014 (Acción de Nulidad).

Corte Suprema, de 6 de junio de 2007, rol № 678-2007 (Acción de Nulidad).

Corte Suprema, de 20 de septiembre de 2006, rol № 3570-2006 (Acción de Nulidad).

Séptimo Tribunal de Juicio Oral en lo Penal de Santiago, de 9 de julio de 2007, rol No $148-2006$.

Séptimo Tribunal de Juicio Oral en lo Penal de Santiago, de 1 de enero de 2007, rol No $148-2006$.

Tribunal de Juicio Oral en lo Penal de Curicó, de 1 de julio de 2006, rol $\mathrm{N}^{\circ} 25-2006$. 